\title{
Effects of Adiabatic Heating and Strain Rate on the Dynamic Response of a CoCrFeMnNi High-Entropy Alloy
}

\author{
G. C. Soares ${ }^{1}$ (D) M. Patnamsetty ${ }^{1}$ (D) P. Peura ${ }^{1}$ D $\cdot$ M. Hokka ${ }^{1}$ (D
}

Received: 30 March 2019 / Revised: 7 July 2019 / Accepted: 24 July 2019 / Published online: 30 July 2019

(c) The Author(s) 2019

\begin{abstract}
This work presents a comprehensive analysis of the effects of strain and strain rate on the adiabatic heating and the mechanical behavior of a $\mathrm{CoCrFeMnNi}$ high-entropy alloy (HEA). In this investigation, compression tests were carried out at quasi-static and dynamic strain rates. The temperature of the specimens was measured using high speed infrared thermography. The high strain rate tests were conducted with a Split Hopkinson Pressure Bar, and the tests at lower strain rates were performed using a universal testing machine. The material exhibited a positive strain rate sensitivity, as true stress-strain plots were shifted upwards with the increase in strain rate. With exception of the isothermal tests, temperature rise and the Taylor-Quinney coefficient $(\beta)$ were noticeably similar for the investigated strain rates. This study shows that the common assumption that $\beta$ can be considered 0.9 and constant is possibly not very accurate for the CoCrFeMnNi alloy. The $\beta$ is influenced by at least strain and strain rate.
\end{abstract}

Keywords Adiabatic heating · Taylor-Quinney coefficient $\cdot \mathrm{CoCrFeMnNi} \cdot$ High-entropy alloy $\cdot$ Dynamic testing $\cdot$ High speed infrared imaging

\section{Introduction}

High-entropy alloys (HEAs) are a new class of multi-component metallic alloys, which comprise four or more elements in equiatomic or near equiatomic composition with high configurational entropy. The so-called Cantor alloy or CoCrFeMnNi alloy was first introduced in 2004 [1], and it is currently the most investigated HEA. The CoCrFeMnNi highentropy alloy has a face-centered cubic crystal structure, which has a large number of slip systems [2] and a unique combination of mechanical strength, malleability, and fracture toughness [3]. Therefore, these alloys are expected to

G. C. Soares

guilherme.correasoares@tuni.fi

M. Patnamsetty

madan.patnamsetty@tuni.fi

P. Peura

pasi.peura@tuni.fi

M. Hokka

mikko.hokka@tuni.fi

1 Engineering Materials Science, Faculty of Engineering and Natural Sciences, Tampere University (TAU), Korkeakoulunkatu 10, 33720 Tampere, Finland be widely used in engineering and military applications. $\mathrm{Li}$ et al. [4] have shown that the $\mathrm{Al}_{0.3} \mathrm{CoCrFeMn}$ high-entropy alloy has remarkable mechanical properties at high strain rates, and that it is a promising alloy for armor applications. Future design and structural applications of HEAs require a better understanding of the thermomechanical response of the alloys during high strain rate deformation.

Temperature and strain rate play important roles on the mechanical behavior of the $\mathrm{CoCrFeMnNi}$ high-entropy alloy and of materials in general $[2,3,5]$. Otto et al. [2] studied the effect of temperature on the tensile properties of a CoCrFeMnNi high-entropy alloy and reported that this alloy exhibits a strong increase in ductility and mechanical strength with decreasing temperature. These authors associated the remarkable properties of the $\mathrm{CoCrFeMnNi}$ alloy at cryogenic temperatures to the occurrence of deformation-induced twinning and dynamic Hall-Petch effect. Park et al. [6] studied the influence of strain rate on the mechanical properties of the $\mathrm{CoCrFeMnNi}$ alloy and reported a substantial yield strength dependence on strain rate, as well as different strain hardening behaviors for different strain rates. Furthermore, they also observed the formation of mechanically induced twins and occurrence of adiabatic shear bands on the samples deformed at dynamic strain rates. On the other hand, $\mathrm{Li}$ et al. [7] studied the formation of 
adiabatic shear bands in the same alloy and concluded that the excellent strain hardenability and low thermal softening provide this alloy a great resistance to shear localization. Kumar et al. [8] investigated the dynamic compressive deformation behavior of an $\mathrm{Al}_{0.1} \mathrm{CrFeCoNi}$ high-entropy alloy and found out the onset of twinning depends on strain rate. The authors also reported that its mechanical behavior was similar to those of materials with low stacking fault energy. Moon et al. [9] and Hong et al. [10] have studied the thermally activated deformation of a CoCrFeMnNi high entropy alloy at room and cryogenic temperatures, and have concluded that the rate controlling mechanism in this alloy is the overcoming of nanoscale obstacles such as short range orders (SROs) and clusters. However, the exact microstructural evolution and especially the high rate thermomechanical behavior of the alloy is still largely unknown.

The Taylor-Quinney coefficient $(\beta)$ can be an interesting parameter to look into, as it describes the fraction of the total plastic work, which is converted to heat during deformation. The Taylor-Quinney coefficient is a measure of how efficiently plastic work is converted into heat during plastic deformation [11, 12]. The research of Farren, Taylor and Quinney [13, 14] on the heat increase during deformation and remaining latent energy after cold working has been the foundation for the research on the conversion of plastic work to heat during deformation. In their initial investigations on copper samples, the authors established that the fraction of plastic work converted to heat during plastic deformation was of approximately 0.9 . Although it has already been established that $\beta$ depends on strain, strain rate, and loading mode [12], the assumption of a constant $\beta$ value of 0.9 for different metallic materials is still common in the recent literature [6, 15-19].

Equations 1 and 2 show the definitions of the $\beta$ in terms of total energy $\left(\beta_{\text {int }}\right)$ and energy dissipation rate $\left(\beta_{\text {diff }}\right)$. Both equations can be derived from the first law of thermodynamics assuming adiabatic conditions, i.e., that no heat conduction occurs. In the Equations $C_{\mathrm{p}}, \mathrm{d} W_{\mathrm{p}}, T$, and $\rho$, stand for heat capacity, incremental plastic work, temperature, and the density of the material. The superposed dotted $W_{\mathrm{p}}$ and $T$ indicate their respective time derivatives.

$$
\beta_{i n t}=\frac{\rho C_{p} \Delta T}{\int d W_{p}}
$$

and

$$
\beta_{\text {diff }}=\frac{\rho C_{p} \dot{T}}{\dot{W}_{p}}
$$

The integral beta $\left(\beta_{\text {int }}\right)$ expresses how much plastic strain energy is converted into heat, and it can be used to evaluate the general temperature increase of a given material with plastic deformation. The differential beta $\left(\beta_{\text {diff }}\right)$ describes the conversion rate of mechanical energy into heat. Unless other heat sources than the plastic deformation are involved then $\beta_{\text {int }}$ is always lower than 1 [12].

$\beta$ describes how much of the plastic work is stored in the microstructure and how much is converted to heat. If the $\beta$ equals one, then the microstructure must be stable as no energy is stored as permanent defects in the structure (vacancies, dislocations, twins, etc.), whereas a lower values of the $\beta$ would indicate a faster evolving structure, in which more energy is stored in the microstructure. For example, Rittel et al. investigated the effect of the dynamic loading mode on $\beta_{\text {int }}$ of Ti alloys, $\mathrm{Al}$ alloys, and steels. The authors reported that $\beta_{\text {int }}$ varied with strain and loading mode, ranging from 0.2 up to 0.9 . The $\mathrm{Al}$ alloys showed a somewhat low $\beta_{\text {int }}$ ranging from 0.2 to 0.4 [12]. Zaera et al. [20] conducted numerical investigations of the $\beta$ in a metastable stainless steel. In their model, the adiabatic conditions are assumed, it is considered that $\beta$ evolves with deformation, and the plastic work done on the different phases was computed separately. They reported that $\beta_{\text {int }}$ and $\beta_{\text {diff }}$ can be greater than one if there are exothermic phase transformations producing extra heat. However, in such case the $\beta$ that is obtained from the temperature measurements no longer has the classic definition based on dislocation theory, but instead the $\beta$ indicates the net heat generated by the material as it is deformed at high rate. In addition, the authors argued that $\beta$ may be different at different locations of the deforming specimen. Smith et al. [21] investigated the $\beta_{\text {int }}$ of a Ti-6Al-4 V alloy under tensile deformation and reported a modest increase of $\beta_{\text {int }}$ at low strains, and an approximately constant $\beta_{\text {int }}$ from 0.5 to 0.7 until failure. Although the $\mathrm{CoCrFeMnNi} \mathrm{high-}$ entropy alloy has been exhaustively studied during the last decades, the effect of adiabatic heating and strain rate on the thermomechanical response of the CoCrFeMnNi highentropy alloy still needs further investigation. The occurrence of softening during high strain rate loading due to adiabatic heating in HEAs has already been suggested in the literature [22], however, not much effort has been done into evaluating and quantifying it. Albeit the high strain rate compression of the $\mathrm{CoCrFeMnNi}$ high-entropy alloy has already been investigated [19], the novelty in this work is the use of the recently developed high speed infrared cameras allowing the assessment of the adiabatic heating and the Taylor-Quinney coefficient of the CoCrFeMnNi highentropy alloy. This work presents a comprehensive analysis of the effects of strain and strain rate on the adiabatic heating, the Taylor-Quinney coefficient, and the mechanical behavior of a $\mathrm{CoCrFeMnNi}$ high-entropy alloy. 


\section{Materials and Methods}

The CoCrFeMnNi high-entropy alloy was cast into a square cross section ingot $(140 \times 40 \times 40 \mathrm{~mm})$ by drop casting in argon atmosphere. The as-cast bar was homogenized in vacuum at $1200{ }^{\circ} \mathrm{C}$ for $12 \mathrm{~h}$, and hot rolled at $1000{ }^{\circ} \mathrm{C}$ into a $400 \times 60 \times 9 \mathrm{~mm}$ plate. Both sides of the plate were carefully ground to approximately $7 \mathrm{~mm}$ thickness, and cylindrical samples with a diameter of $8 \mathrm{~mm}$ were EDM machined from the plate. Three compression tests were carried out at quasi-static $\left(3 \times 10^{-4}, 10^{-2}\right.$, and $1 \mathrm{~s}^{-1}$ ) and dynamic $\left(750\right.$ and $\left.2800 \mathrm{~s}^{-1}\right)$ strain rates. The microscopy samples were cut parallel to the compression axis and sectioned samples were mechanically polished for microscopy and EBSD analyses. The temperature of the specimens was measured during the test using a high performance Telops FAST-IR 2K high speed infrared camera with a $50 \mathrm{~mm}$ lens. Imaging rate of $90 \mathrm{kHz}$ was used for the high strain rate tests, which gives the temperature measurements only every $11 \mu \mathrm{s}$. Higher sampling frequencies would be preferable and would be required for detailed determination of the $\beta$, especially at low strains. Also for small changes in the $\beta$ as a function of plastic strain, much higher imaging frequencies would be needed at the strain rates of 750 and $2800 \mathrm{~s}^{-1}$. However, this camera is currently the best available on the market. Hopefully, faster infrared technology will allow higher temporal resolution of the measurements in the future. The high strain rate tests were carried out with a compression Split Hopkinson Pressure Bar (SHPB) device, and the tests at lower strain rates were performed using an Instron 8800 universal testing machine. The experimental setup used in this investigation for both dynamic and quasi-static tests are shown in Fig. 1.

The SHPB device comprise two high strength steel bars with $1200 \mathrm{~mm}$ length and $22 \mathrm{~mm}$ diameter, as well as striker bars with lengths of 200,300 , or $400 \mathrm{~mm}$. The incident, transmitted, and reflected stress pulses were measured with $5 \mathrm{~mm}$ strain gages attached to the bars. The signals were amplified by a Kyowa CDV 700A series signal conditioner, and recorded with a 12-bit MSample Yokogawa digital oscilloscope. A numerical dispersion correction adopted from the work of Gorham \& Wu [23] was used to correct the effect of longitudinal wave dispersion on the measured strain data. The stress, strain, and strain rate were then calculated from the dispersion corrected pulses.

The image acquisition trigger signals were recorded with the same oscilloscope within the same timeframe as the strain pulses from the stress bars. This allowed temporal matching of the calculated stress-strain curves and the temperature data obtained from the infrared camera. A calibration from radiometric temperatures to true surface temperatures was obtained by comparing the infrared image data and temperature data measured with thermocouples. The calibration data was obtained by slowly heating up the sample in similar conditions and setup as the one in which the tests were performed. Three calibration measurements were carried out using the same experimental setup as for the Hopkinson Bar experiments. These measurements were used to create an average calibration and the associated standard error of the mean. Figure 2 shows an example of a calibration curve for the Cantor alloy with an integration time of $5 \mu$ s from room temperature up to $257^{\circ} \mathrm{C}$. The standard error of the mean increased with temperature and its maximum observed value was of $1.6^{\circ} \mathrm{C}$ at the surface temperature of $256{ }^{\circ} \mathrm{C}$.

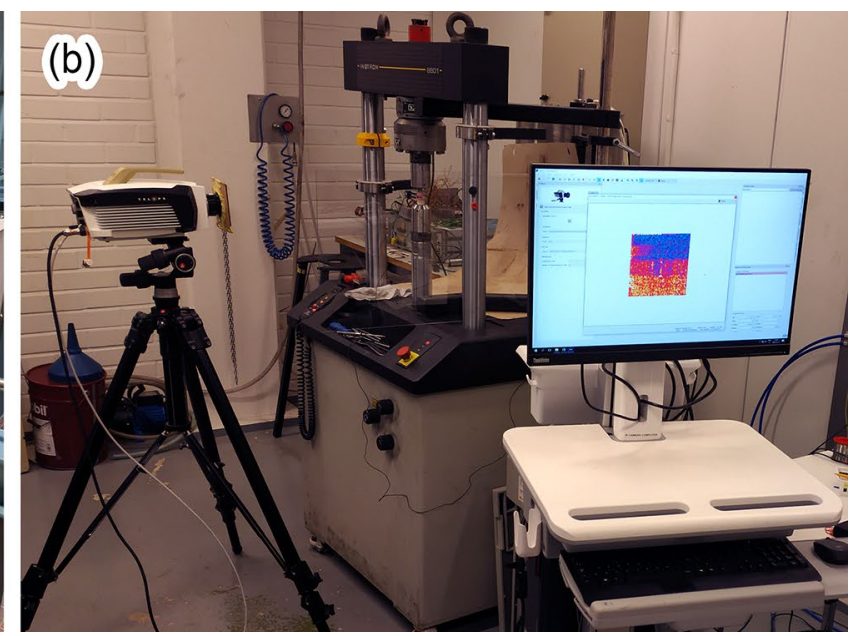

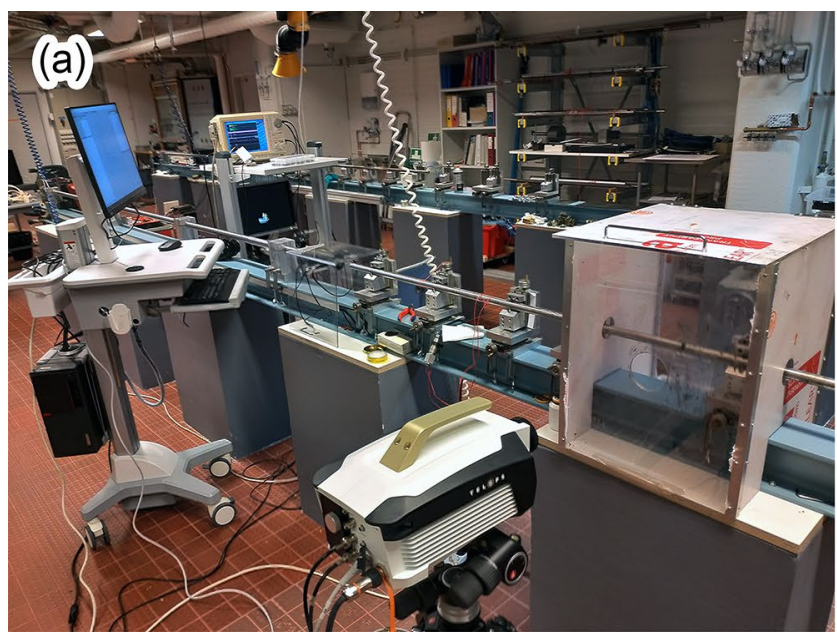

Fig. 1 Experimental setup comprising the high performance IR camera and a compression Split Hopkinson Pressure Bar device for dynamic tests, and $\mathbf{b}$ Instron servohydraulic testing machine for quasi-static tests 


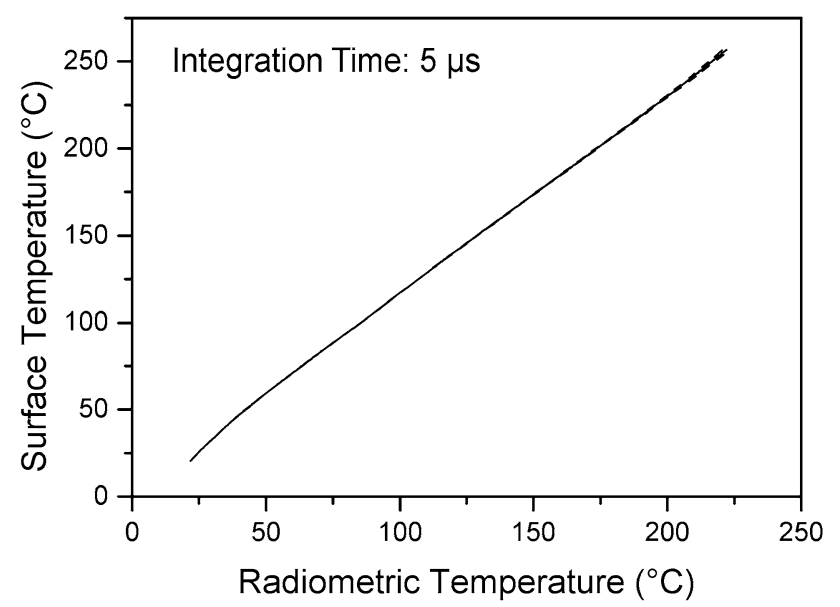

Fig. 2 Average radiometric temperature of three measurements as a function of surface temperature with an integration time of $5 \mu \mathrm{s}$. The standard error of the mean is represented as the dashed lines neighboring the solid line, which represents the average of the three measurements

The strain hardening exponent $(n)$ and strength coefficient $(K)$ of the Hollomon equation (Eq. 3) were determined from the stress strain plots. Furthermore, the strain hardening rate and the instantaneous strain hardening exponent $\left(n_{\mathrm{i}}\right)$ were determined as function of strain. Both the differential $\left(\beta_{\text {diff }}\right)$ and the integral $\left(\beta_{\text {int }}\right)$ Taylor-Quinney coefficient, were calculated for the dynamic tests as a function of plastic strain. For the quasi-static tests at the strain rate of $1 \mathrm{~s}^{-1}$, only an approximation of the Taylor-Quinney factor was obtained ignoring the minor conduction of heat that may occur during the tests at this condition. The possible heat conduction during the tests at the strain rate of $1 \mathrm{~s}^{-1}$ was very low as no temperature gradients were observed in the full field temperature measurements. Any gradient would be an indication of heat conducting from the specimen to the anvils. No $\beta$ values below strain rate of $1 \mathrm{~s}^{-1}$ are reported in this paper as the measurements would require a meticulous analysis of the heat transfer involved. For the calculations of the $\beta$, a $C_{\mathrm{p}}$ of $430 \mathrm{~J} / \mathrm{kg} \mathrm{K}$ and a $\rho$ of $7.958 \mathrm{~g} / \mathrm{cm}^{3}$ were used [6].

$\sigma=K \times \varepsilon^{n}$

Scanning electron microscope (SEM) images of the as rolled and deformed samples were obtained with a JEOL JSM IT500 equipped with an energy-dispersive X-ray spectroscopy (EDS) detector. Electron backscatter diffraction (EBSD) band contrast images and inverse polar figure maps were obtained using a Zeiss ULTRAplus SEM equipped with Oxford Instruments Symmetry CMOS EBSD detector operated at an accelerating voltage of $20 \mathrm{kV}$ and a step size of $0.7 \mu \mathrm{m}$. The initial austenitic structure of the material was confirmed with a PANalytical Empyrean Multipurpose
Table 1 Chemical composition of the CoCrFeMnNi high-entropy alloy obtained by EDS (at.\%)

\begin{tabular}{lllll}
\hline $\mathrm{Cr}$ & $\mathrm{Mn}$ & $\mathrm{Fe}$ & $\mathrm{Co}$ & $\mathrm{Ni}$ \\
\hline $19.5 \pm 0.1$ & $20.4 \pm 0.2$ & $19.8 \pm 0.3$ & $20.2 \pm 0.2$ & $20.2 \pm 0.2$ \\
\hline
\end{tabular}

Diffractometer with a Bragg-Brentano geometry and using $\mathrm{Cu} \mathrm{K} \alpha$ radiation.

Grain size distribution, grain boundary character distribution, and twin density were analyzed from the EBSD measurements. A scanning area of approximately $370 \times 250 \mu \mathrm{m}$ and a step size of $0.7 \mu \mathrm{m}$ was analyzed. The rolling direction of the analyzed area in the hot rolled sample is towards the $\mathrm{X}$-axis, while the normal direction is towards the $\mathrm{Y}$-axis. A critical misorientation angle of $15^{\circ}$ was selected for the grain size determination and the grains with $<10$ pixels were removed to reduce the noise. Additionally, grain boundary regions were excluded from the grain size determination.

Recrystallization fraction maps were used to evaluate the internal average misorientation angle and the deformation levels within each grain. The grain was defined as a deformed grain if the average grain angle exceeded the defined minimum angle of $2^{\circ}$. The grain was classified as a substructured grain if the grain was composed of subgrains whose internal misorientations were $<2^{\circ}$, but the misorientation between the subgrains was higher than $2^{\circ}$. The remaining grains were then considered recrystallized grains. From this classification, the recrystallized grains are the least deformed, the substructured grains have an intermediate amount of deformation, and the deformed grains are the most deformed. Furthermore, to further evaluate the texture of the material, pole figures were drawn with a $\mathrm{X} 1$-axis parallel to the rolling direction and $\mathrm{Y} 1$ is parallel to the normal direction.

Table 1 shows the chemical composition of the investigated alloy. The standard error of the mean were obtained from averaging three EDS measurements. Figure 3 shows the inverse pole figure (IPF), grain boundary (GB), recrystallization fraction maps, and the XRD pattern of the hot rolled cantor alloy. The high misorientation angle $\left(\theta>15^{\circ}\right)$ and low misorientation angle $\left(2^{\circ} \leq \theta \leq 15^{\circ}\right)$ are highlighted in black and green lines respectively. The average grain size of the hot rolled material is approximately $9.15 \mu \mathrm{m}$ (including twin boundaries). The annealing twins [ $\Sigma 3$ twin boundaries (highlighted in red)] that were formed during hot rolling are around 6.6\% as shown in Fig. 3b. In Fig. 3c the recrystallized fraction is $3.70 \%$, substructured is $86.5 \%$, and the deformed fraction $9.8 \%$. This fraction of recrystallized grains shows dynamic recrystallization behavior in few grains during hot rolling at $1000{ }^{\circ} \mathrm{C}$. The XRD analysis confirmed that the samples possessed a single phase and a FCC crystalline structure. 

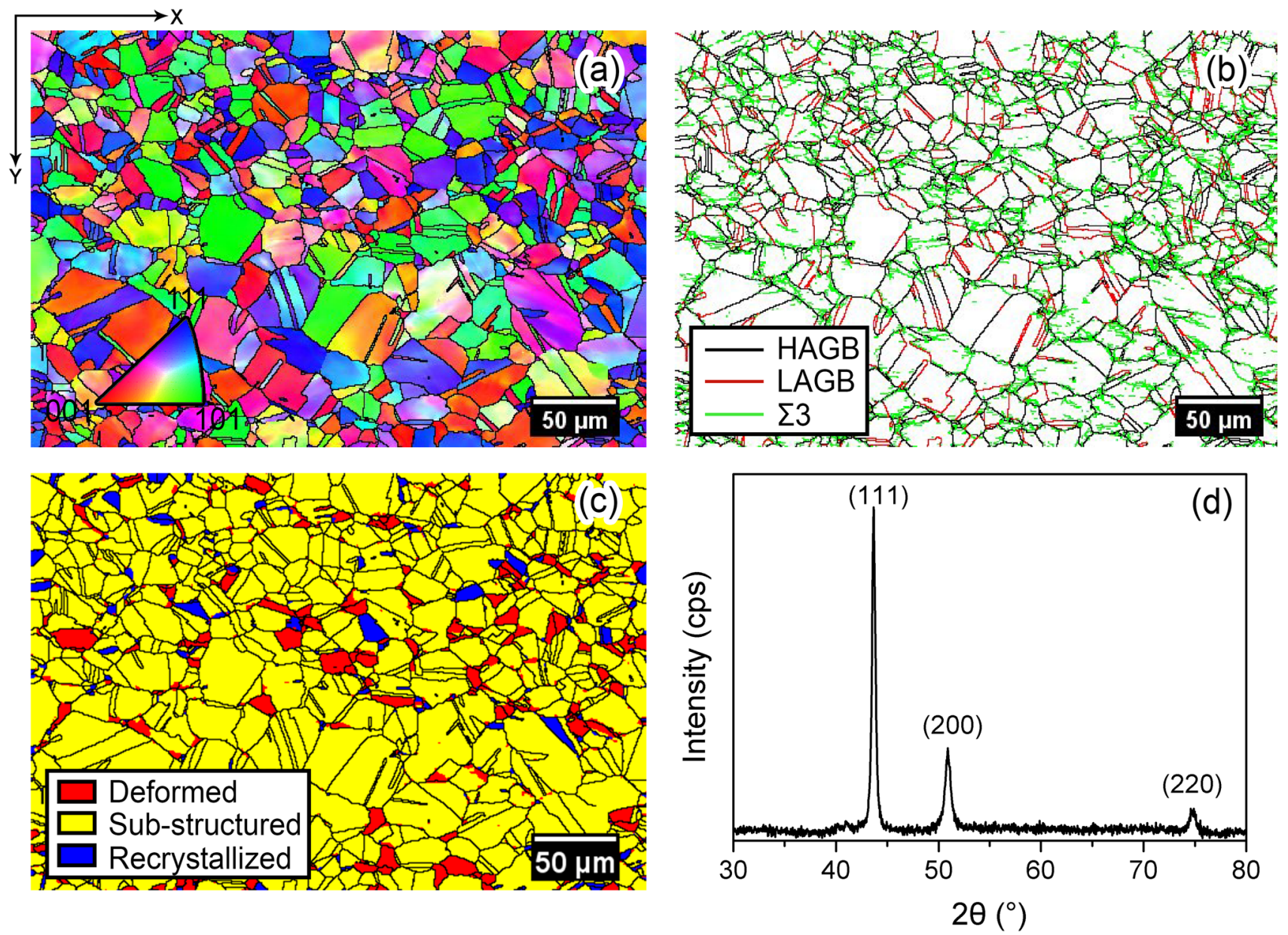

Fig. 3 a Inverse pole figure $\mathbf{b}$ grain boundary map c recrystallization fraction map, and $\mathbf{d}$ X-ray diffraction pattern of the hot rolled CoCrFeNiMn HEA. The $\mathrm{X}$ axis represents the rolling direction and the $\mathrm{Y}$ axis represents the normal direction
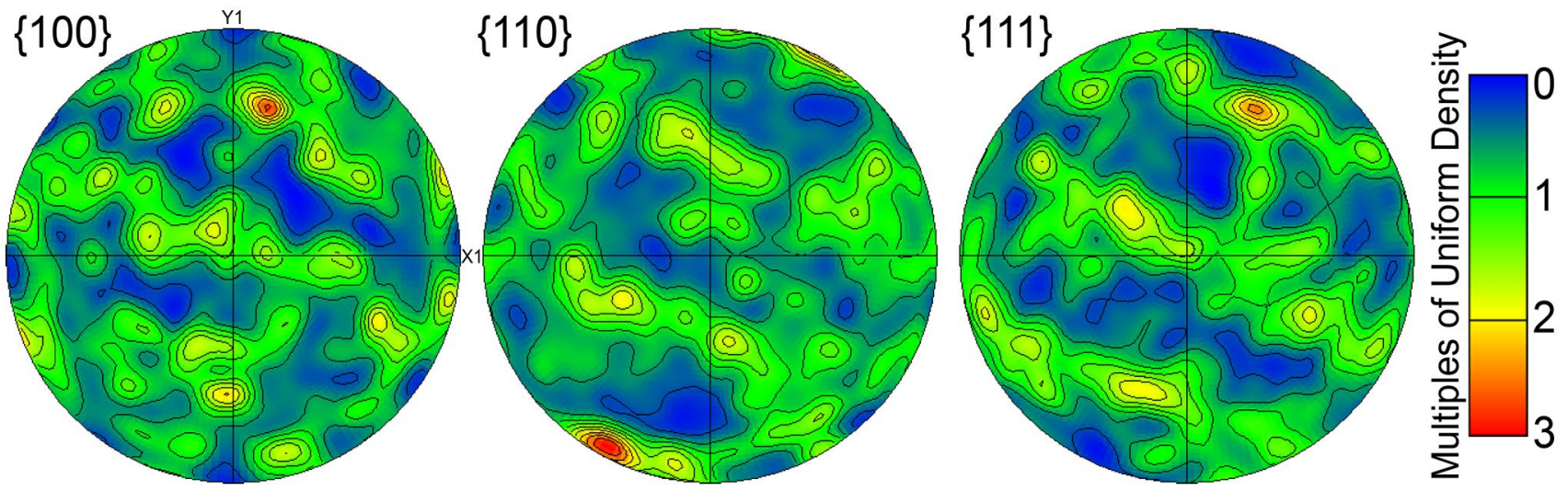

Fig. $4\{100\},\{101\}$, and $\{111\}$ Pole Figures of the hot rolled CoCrFeNiMn alloy

Figure 4 shows the $\{100\},\{101\}$, and $\{111\}$ pole figures for the contoured intensities of the hot rolled CoCrFeNiMn. The contour density of from all the pole figures is distributed randomly with a maximum multiples of uniform density (MUD) value around 3, the same is visible in the Fig. 3a, in which all the individual grains are randomly oriented in all three orientations. 


\section{Results and Discussion}

\section{Microstructural Evolution}

Figure 5a-c show IPF color maps of samples compressed to true strains of $0.55,0.55$, and 0.50 at the strain rates of $3 \times 10^{-4}, 1$ and $2800 \mathrm{~s}^{-1}$. The grain size analysis, recrystallization fraction analysis and twins are given in Table 2. The Y1 is the compression axis. The microstructural evolution shows that the grains were slightly elongated towards the perpendicular direction to the compression axis (X1 axis) at the strain rate $3 \times 10^{-4} \mathrm{~s}^{-1}$. Additionally, there are smaller grains formed along the grain boundaries after compression at strain rates 1 and $2800 \mathrm{~s}^{-1}$. Decrease in the grain size occurred with a decrease in the twin boundary fraction, as shown in Table 2. At the strain rate of $2800 \mathrm{~s}^{-1}$, the fraction of the recrystallized grains increased, possibly due to the occurrence of dynamic recrystallization (DRX). DRX could have been caused by the strong shear localization. Additionally, it is seen that the $\Sigma 3$ twin boundaries percentage is increased. This is further confirmed by the fact that the boundary misorientation frequency at $60^{\circ}$ was higher, which corresponds to
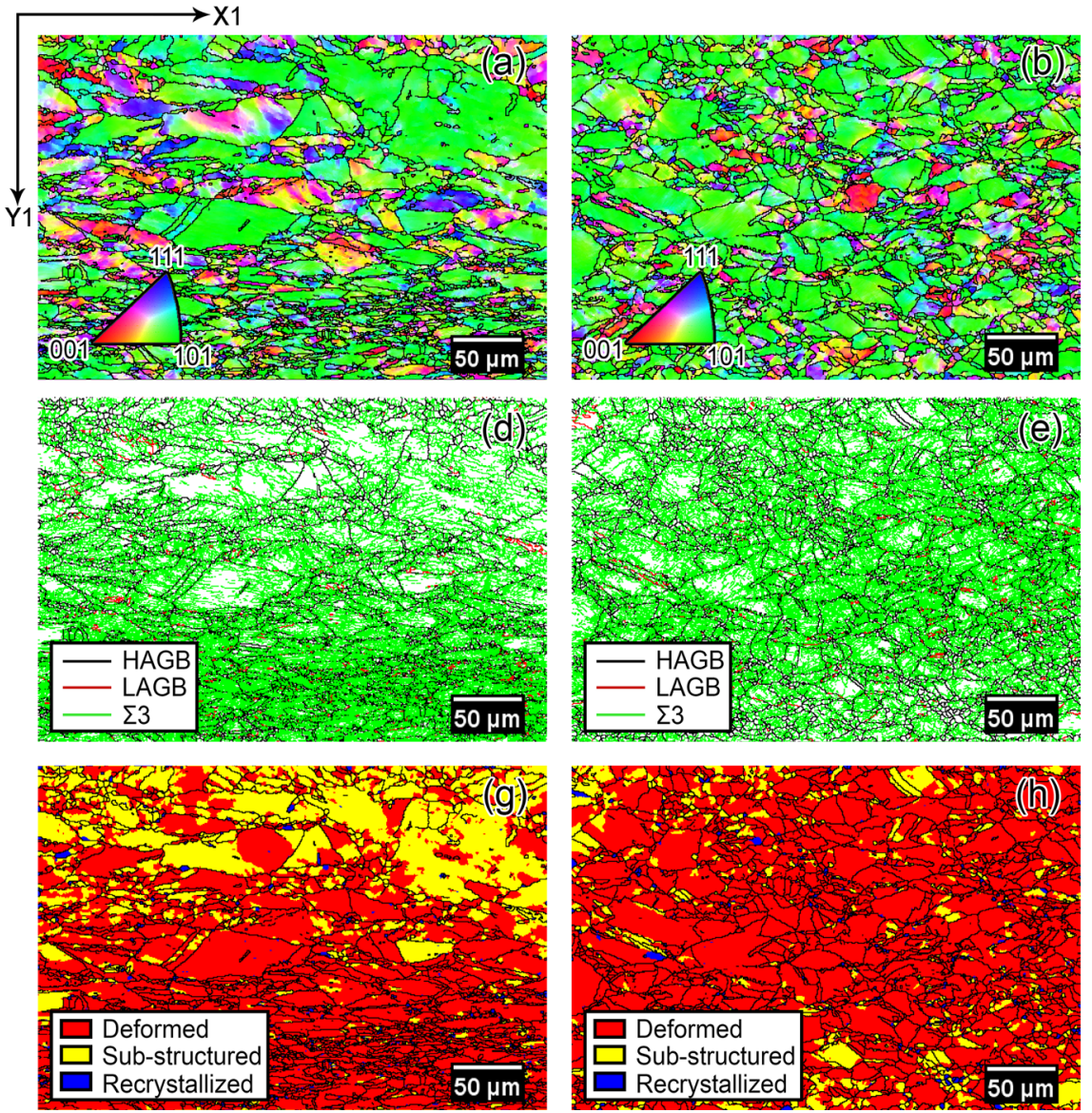
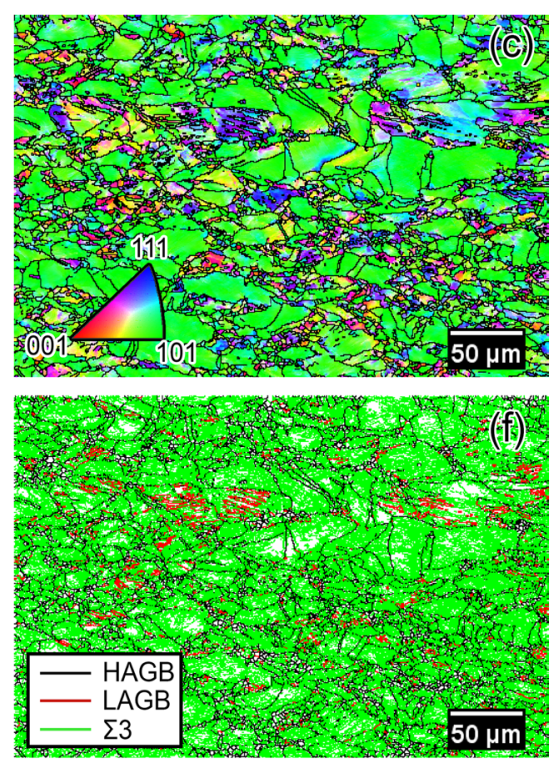

Fig. 5 a-c IPF color maps; $\mathbf{d}-\mathbf{f}$ GB maps, and $\mathbf{g}-\mathbf{i}$ recrystallization fraction maps of the samples deformed to 0.55 strain at a strain rate of $3 \times 10^{-4} \mathrm{~s}^{-1}(\mathbf{a}, \mathbf{d}, \mathbf{g})$, to 0.55 strain at a strain rate of $1 \mathrm{~s}^{-1}(\mathbf{b}, \mathbf{e}, \mathbf{h})$, and to 0.5 strain at a strain rate of $2800 \mathrm{~s}^{-1}$ (c, f, i) (Color figure online)

Table 2 Grain size analysis, recrystallization fraction, and twin percentage analyses obtained from EBSD

\begin{tabular}{lllllll}
\hline Strain rate $\left(\mathrm{s}^{-1}\right)$ & Total strain & Grain size $(\mu \mathrm{m})$ & \multicolumn{2}{l}{ Recrystallization fraction $(\%)$} & \multicolumn{2}{c}{ Twin $\Sigma 3 \%$} \\
\cline { 3 - 6 } & & & Recrystallized & Substructured & Deformed \\
\hline NA (hot rolled) & As-received & $9.1 \pm 39.0$ & 3.7 & 86.5 & 9.8 & 6.6 \\
$3 \times 10^{-4}$ & 0.55 & $6.0 \pm 22.9$ & 2.3 & 27.3 & 70.4 & 0.8 \\
1 & 0.55 & $6.5 \pm 21.9$ & 2.1 & 11.9 & 86.0 & 0.7 \\
2800 & 0.5 & $5.4 \pm 18.0$ & 4.5 & 9.7 & 85.9 & 2.3 \\
\hline
\end{tabular}


the $60^{\circ}<111>$ twinning relationship. Thus, the increase in these $\Sigma 3$ twin boundaries fraction boundaries could be due to DRX.

Figure 6 shows the $\{100\},\{101\}$, and $\{111\}$ pole figures of the samples deformed at strain rates of $3 \times 10^{-4}, 1$ and $2800 \mathrm{~s}^{-1}$. In the pole figures for all deformed samples, the contour density of $\{101\}$ pole figure is the most intensive. Thus at all strain rates, the compression direction (Y1) is parallel to most of the grains which have $\{101\}$ orientation. The same is seen in Fig. $5 \mathrm{a}-\mathrm{c}$ where most of the grains have
$\{101\}$ orientation. Additionally, the maximum MUD values increased from 4.55 to 5.36, with increase in the strain rates. This means that the intensity of fiber texture $\{101\}$ is strain rate dependent, i.e. the intensity increases with strain rate.

\section{Thermomechanical Analysis}

Figure $7 \mathrm{a}$ shows the true stress-true plastic strain curves, Fig. $7 \mathrm{~b}$ the temperature rise, Fig. $7 \mathrm{c}$ the strain hardening rate, and the Fig. $7 \mathrm{~d}$ the instantaneous strain hardening
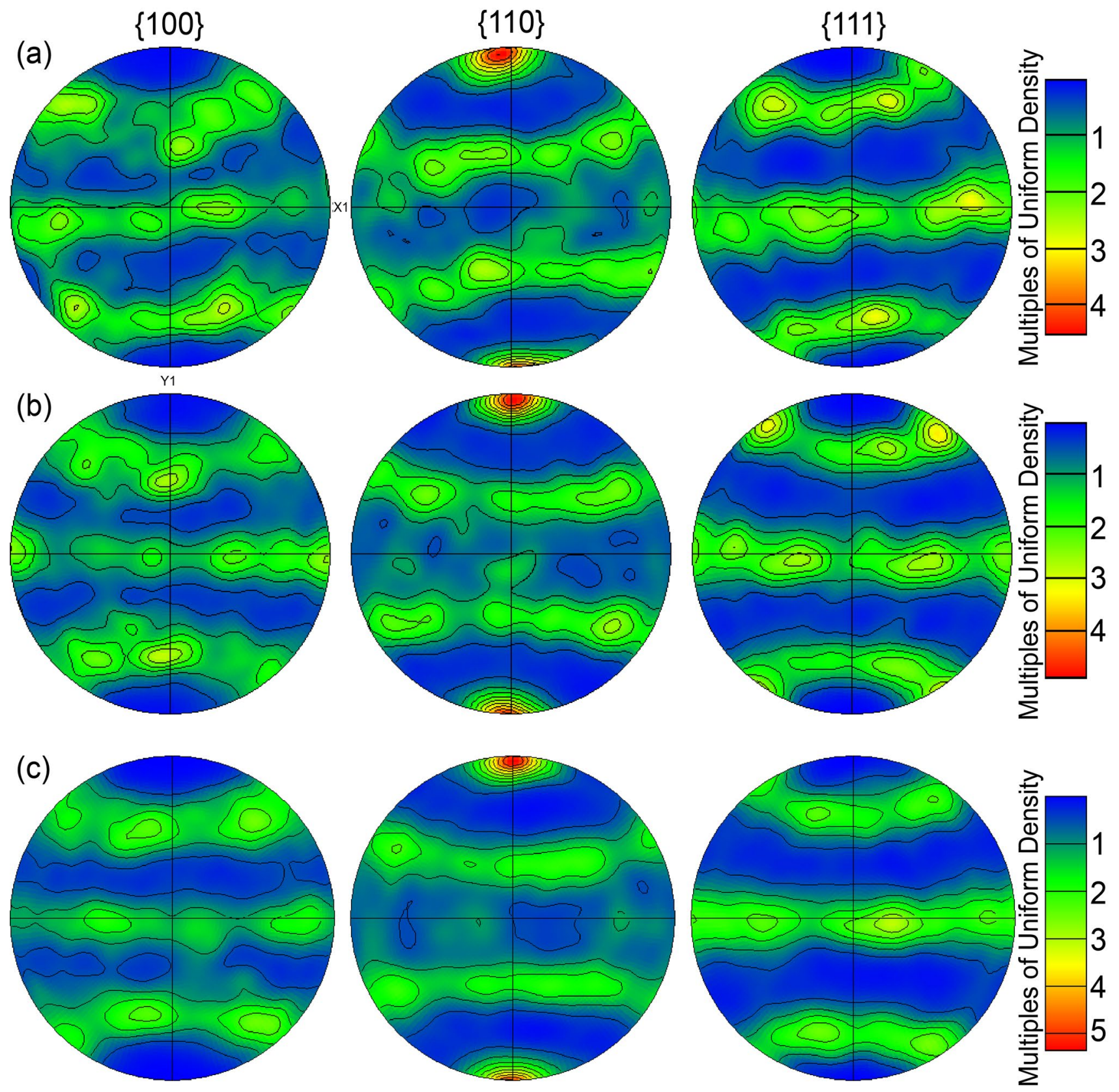

Fig. $6\{100\},\{101\}$, and $\{111\}$ pole figures of the samples deformed to a 0.55 strain at a strain rate of $3 \times 10^{-4} \mathrm{~s}^{-1}, \mathbf{b} 0.55$ strain at a strain rate of $1 \mathrm{~s}^{-1}$, and 0.5 strain at a strain rate of $2800 \mathrm{~s}^{-1}$ 

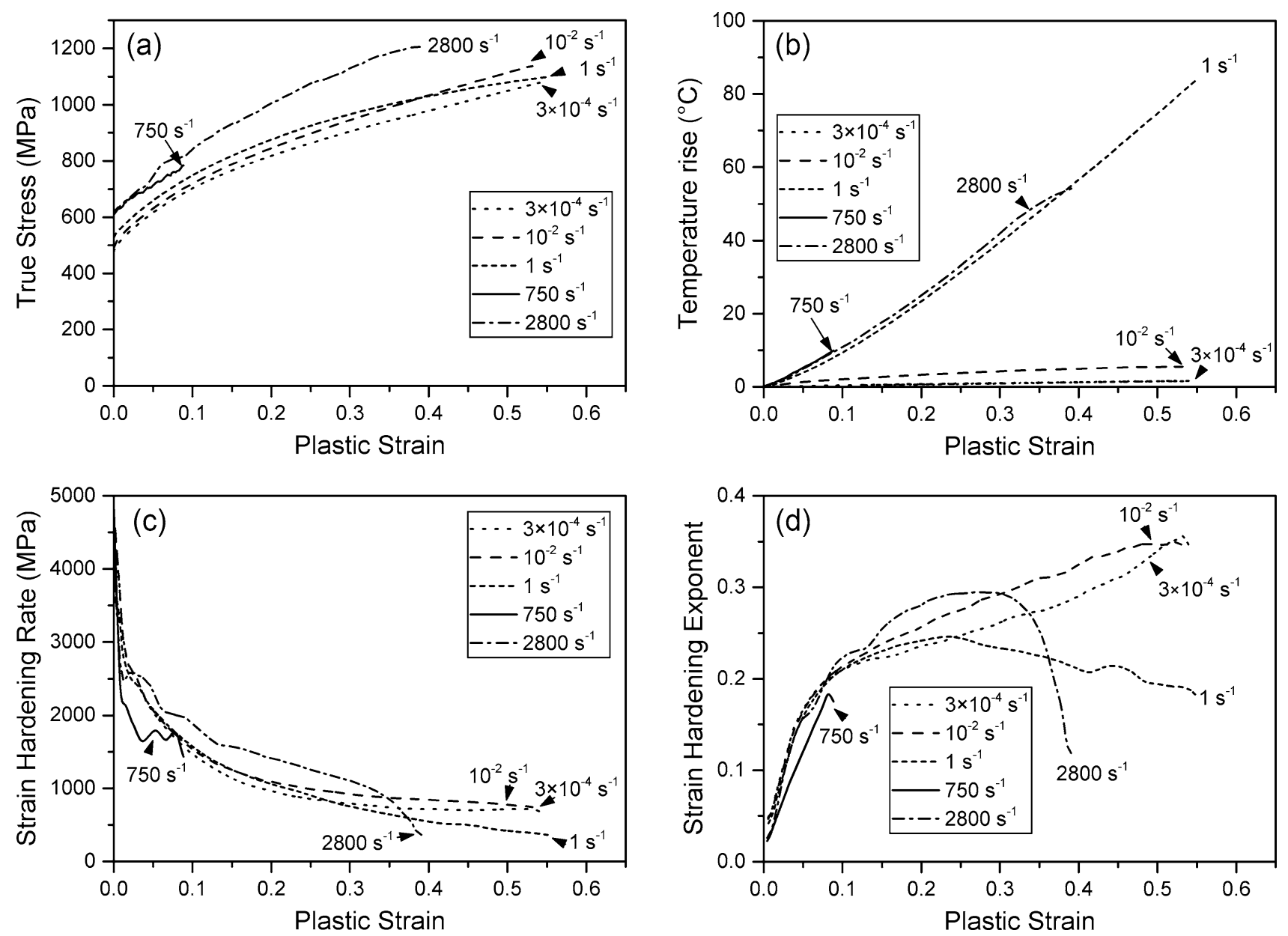

Fig. 7 a True stress - true plastic strain $\mathbf{b}$ temperature rise as a function of plastic strain $\mathbf{c}$ strain hardening rate, and $\mathbf{d}$ instantaneous strain hardening exponent as a function of true strain at different strain rates

exponent as a function of plastic strain at different strain rates. The material has a positive strain rate sensitivity, as mechanical strength increases with strain rate. Table 3 shows the yield strength and the strain hardening exponent $n$ and the constant $K$ of the Hollomon Equation at different strain rates. The presented values are average of two or three tests, and are shown with their standard error of the mean. Yield strength was determined by backward extrapolation of the flow curve. At the strain rate of $3 \times 10^{-4} \mathrm{~s}^{-1}$ the yield strength of the material was $475 \pm 3 \mathrm{MPa}$ and at strain rate of $2800 \mathrm{~s}^{-1}$ the yield strength increased to $605 \pm 3 \mathrm{MPa}$. This great increase in yield strength from quasi-static to dynamic testing conditions is typically explained by the activation of the phonon drag effect on dislocation motion during high strain rate deformation [24]. At the strain rate of $3 \times 10^{-4} \mathrm{~s}^{-1}$ the flow stress of the material was $915 \mathrm{MPa}$ at a true strain of 0.32 , whereas the corresponding flow stress was $1153 \mathrm{MPa}$ at the strain rate of $2800 \mathrm{~s}^{-1}$. The higher increase in flow stress from yielding to a strain of 0.32 at the strain rate of $2800 \mathrm{~s}^{-1}$ indicate stronger strain hardening at higher strain rate, even though the thermal softening is taking place at the higher strain rate. A nearly constant strain hardening exponent of approximately 0.18 was observed for all studied strain rates, while an increase in the Hollomon strength
Table 3 Yield strength, the Hollomon strain hardening exponent, and strength coefficient at strain rates of $3 \times 10^{-4} \mathrm{~s}^{-1}$ up to $2800 \mathrm{~s}^{-1}$

\begin{tabular}{lccccc}
\hline & $3 \times 10^{-4} \mathrm{~s}^{-1}$ & $10^{-2} \mathrm{~s}^{-1}$ & $1 \mathrm{~s}^{-1}$ & $750 \mathrm{~s}^{-1}$ & $2800 \mathrm{~s}^{-1}$ \\
\hline $\begin{array}{l}\text { Yield strength } \\
\text { (MPa) }\end{array}$ & $475 \pm 3$ & $490 \pm 1$ & $520 \pm 2$ & $610 \pm 19$ & $605 \pm 3$ \\
$n$ & $0.181 \pm 0.003$ & $0.194 \pm 0.001$ & $0.183 \pm 0.005$ & - & $0.190 \pm 0.005$ \\
$K(\mathrm{MPa})$ & $1125 \pm 6$ & $1190 \pm 0$ & $1195 \pm 11$ & - & $1385 \pm 9$ \\
\hline
\end{tabular}


coefficient $K$ was observed with the increase in strain rate. The $K$ increased from roughly $1170 \mathrm{MPa}$, for all quasi-static strain rates, to $1365 \mathrm{MPa}$ at the strain rate of $2800 \mathrm{~s}^{-1}$. At the strain rate of $750 \mathrm{~s}^{-1}$ the total strain was too low to obtain reliable parameters of the Hollomon Equation.

The temperature rise increased with strain rate, and the measured temperature rise for the strain rates of $1 \mathrm{~s}^{-1}$, $750 \mathrm{~s}^{-1}$, and $2800 \mathrm{~s}^{-1}$ was notably similar. The total temperature rise for the samples tested at the strain rates of $3 \times 10^{-4} \mathrm{~s}^{-1}$ and $10^{-2} \mathrm{~s}^{-1}$ were of approximately $1.5 \pm 0.2$ and $5.5 \pm 0.1^{\circ} \mathrm{C}$. Although the tests performed at $750 \mathrm{~s}^{-1}$ only had a total plastic strain of 0.09 , a temperature rise of $10 \pm 0.5^{\circ} \mathrm{C}$ was observed.

For all studied strain rates, the strain hardening rate was very high in the beginning of the test, but then quickly decreased at strains above 0.05 . The hardening rate slowly decreased further towards higher strains. The flow strength at $1 \mathrm{~s}^{-1}$ is initially higher than the one observed for strain rates of $10^{-2}$ and $3 \times 10^{-4} \mathrm{~s}^{-1}$. However, the strain hardening rate of the material is higher at the lower strain rates, and the strength of the material at the strain rate of $10^{-2} \mathrm{~s}^{-1}$ is actually higher than the strength at the strain rate of $1 \mathrm{~s}^{-1}$ at strains higher than 0.4. This is most likely caused by adiabatic heating and thermal softening of the material. The strain hardening rate at quasi static conditions matches fairly well with that found in the literature [2, 6, 25]. However, Park et al. [6] reported that at the Cantor alloy tested at a strain rate of $4700 \mathrm{~s}^{-1}$ had a higher strain hardening rate than at a strain rate of $10^{-4} \mathrm{~s}^{-1}$. They explained the increase in hardening rate by increased mechanical twinning at $4700 \mathrm{~s}^{-1}$. It is known that higher strain rates favor the formation of nanotwins in FCC HEAs [26] and that twinning is a major deformation mechanism of the CoCrFeMnNi HEA at cryogenic temperatures [2]. However, only a modest increase in strain hardening rate at low strains $(\varepsilon=0.01-0.1)$ was observed for the samples tested at 750 and $2800 \mathrm{~s}^{-1}$. The propensity for mechanical twinning depends on grain size, which could explain the differences in the strain hardening behavior at dynamic strain rates observed in the current investigation in comparison with the one reported by Park et al. [6].

At lower plastic strains, the instantaneous strain hardening exponent, $n_{\mathrm{i}}$, was somewhat similar for all investigated strain rates and increased to approximately 0.2. Thereafter the $n_{\mathrm{i}}$ increased with strain throughout the tests conducted at the strain rates of $3 \times 10^{-4}$ and $10^{-2} \mathrm{~s}^{-1}$. In the tests at strain rates of 1 and $2800 \mathrm{~s}^{-1}, n_{\mathrm{i}}$ rose to a maximum and then decreased until the end of the test.

At low strain rates, the overall shape of the stress-strain plot or the strain hardening rate of the material does not change much when strain rate is increased. That is not very typical behavior for an FCC metal, where the thermal component of the flow stress is strongly governed by dislocation intersections, and the amount of the thermal activation, i.e., rate sensitivity, increases with plastic strain as the overall dislocation density increases. The strain rate sensitivity of the $\mathrm{CoCrFeMnNi}$ alloy seems quite insensitive to plastic strain at least for strains below 0.25 and strain rates below $2800 \mathrm{~s}^{-1}$. This indicates that the thermally activated mechanisms of dislocation motion are not strong functions of strain. The Peierls stress, for instance, is such a thermally activated mechanism that does not depend on the amount of plastic strain, but depend more on the elastic constants and size and shape of the unit cell [24]. For a high-entropy alloy, the lattice friction (Peierls stress) can be much higher than for a low alloy FCC metal due to its large lattice distortions, strong solid solution strengthening, and higher interaction energy between dislocations and solute atoms [27, 28]. Hong et al. [10] and Moon et al. [9] have investigated the rate controlling mechanism of the $\mathrm{CoCrFeMnNi}$ alloy and reported that its activation volume for deformation is closer to that observed in BCC metals. The authors concluded that the high friction stress for dislocation motion to be the rate controlling mechanism in this alloy. Both studies argued that the presence of nanoscale obstacles such as clusters and SROs lead to a high friction stress for dislocation motion. Furthermore, dislocation movement in such a highly distorted lattice does not occur through the usual kink-pair mechanism but via wavy dislocation gliding, which involve a large activation volume and could be the reason for the low rate sensitivity of strain hardening observed in the current work [28].

Both the strain hardening rate and the instantaneous strain hardening exponent reflect the rate at which the structure of the material is changing, while the current value of the strength reflects the current microstructure. In this work, the strain hardening rate first decreases as the strain rate is increased. The lowest strain hardening rate occurs at the strain rate of $1 \mathrm{~s}^{-1}$ at high plastic strains $(>0.30)$. At higher strain rates the strain hardening rate again increases, and the highest hardening rates are observed at strain rates of $2800 \mathrm{~s}^{-1}$. The permanent hardening due to increase of dislocation density, twins, and other microstructural changes is simultaneously accompanied by thermal softening of the material at higher strain rates and plastic strains. A sample deformed at a strain rate of $1 \mathrm{~s}^{-1}$ would already have a temperature rise of $40 \pm 1{ }^{\circ} \mathrm{C}$ at a plastic strain of 0.3 , and the one deformed at $2800 \mathrm{~s}^{-1}$ would have had its temperature increased by $42 \pm 1{ }^{\circ} \mathrm{C}$. Such modest increase in temperature cannot have caused strong thermal softening and is not significant in terms of the decrease of the absolute strength of the material. The increase in strain rate and the adiabatic heating seem therefore to have a stronger effect in the permanent strengthening of the material. Nevertheless, the strain hardening rate continuously decreases with plastic strain, and the decrease is faster at higher plastic strains at all investigated strain rates. This can be due to many reasons related 
to the microplastic deformation mechanisms, e.g., changes in the cross-slip behavior of dislocations at higher flow stresses, strain induced twinning, etc. that will change with strain rate. Typically this is because towards higher plastic strains, the microstructure of the material simply saturates and the dislocation and defect structures evolve less. The evolution is clearly a function of strain rate. However, without extensive Transmission Electron Microscopy these conclusions cannot be confirmed for the studied Cantor alloy.

Figure 8 shows the $\beta_{\text {int }}$ and $\beta_{\text {diff }}$ as a function of strain at different strain rates. These values are shown as averages with standard error of mean obtained from two or three tests. For all studied strain rates, the values of the $\beta$ vary between approximately 0.4 and 0.6 . However, at the strain rate of $2800 \mathrm{~s}^{-1}$, the $\beta_{\text {diff }}$ abruptly decreased at a plastic strain value of roughly 0.25 . Also it seems that the $\beta_{\text {diff }}$ or $\beta_{\text {int }}$ may have a different behavior in the lower plastic strain region $(\varepsilon<0.05)$ and at medium or higher plastic strains. However, due to
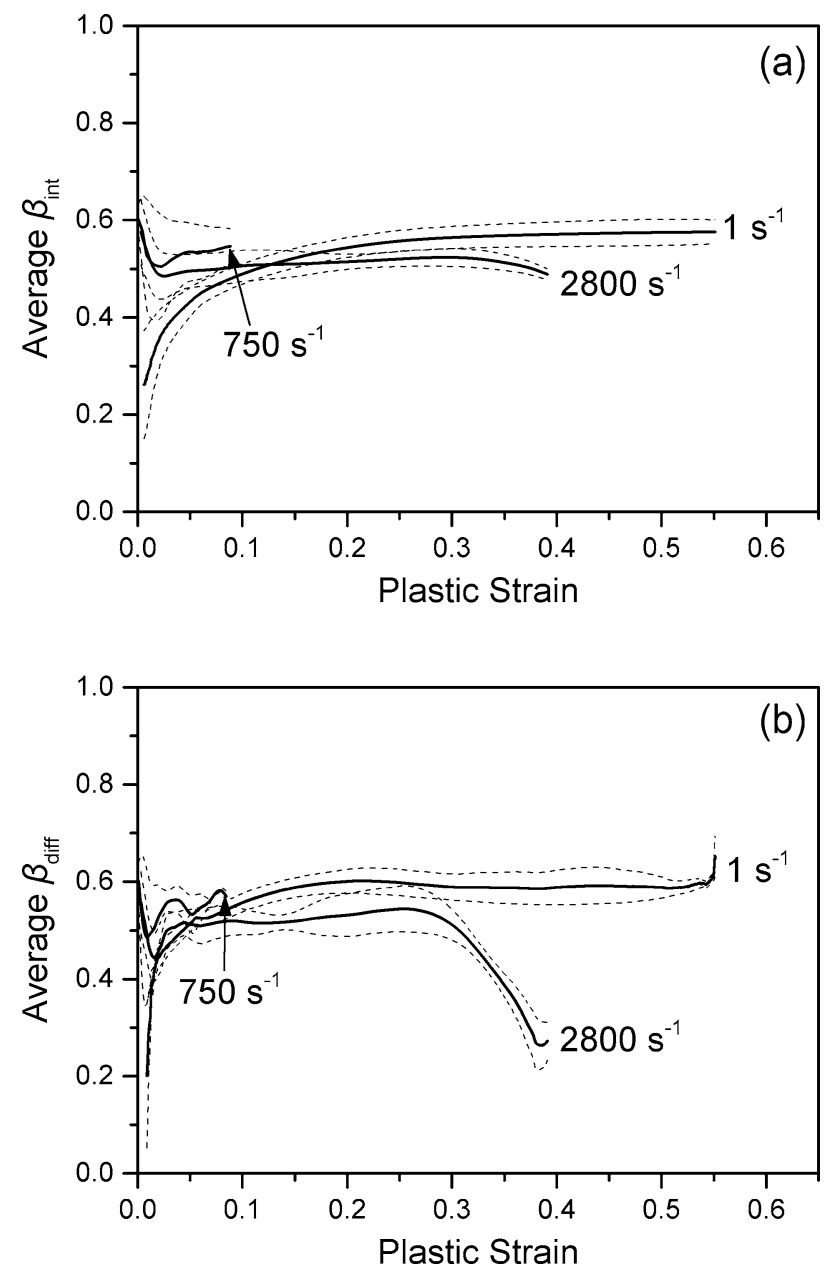

Fig. 8 a $\beta_{\text {int }}$ and $\mathbf{b} \beta_{\text {diff }}$ as a function of true strain for the CoCrFeMnNi high-entropy alloy. The results are shown with their standard error of mean the low temporal resolution of the infrared imaging this observation cannot be conclusively confirmed, and more investigations are required. The calculated $\beta$ values differ considerably from the ones reported for other FCC alloys on the literature. Rittel et al. [12] reported a constant value of $\beta_{\text {int }}$ of 0.3 for an $\mathrm{Al} 2024$ alloy deformed at approximately $2750 \mathrm{~s}^{-1}$, and a $\beta_{\text {int }}$ that decreased from 0.6 to 0.4 for austenitic $304 \mathrm{~L}$ steel over a plastic strain of 0.3 . Zaera et al. [20] numerically investigated $\beta_{\text {int }}$ and $\beta_{\text {diff }}$ on a 304 stainless steel under compression at a strain rate of $900 \mathrm{~s}^{-1}$ and found out values of approximately 0.9 for both coefficients over a strain range of 0.4 . Therefore, considering this numerical investigation, it appears that the $\beta$ behavior of a material has no clear relationship with the material crystallographic structure.

This distinct behavior at low plastic strains observed in the $\beta$, strain hardening rate, and $n_{\mathrm{i}}$ suggests that the strain hardening behavior comprises at least two different stages. This has also been indicated in the recent literature [6]. It is known that the investigated alloy tends to form a more recovered and soft cellular dislocation substructure at high plastic strain values [2]. Both the $\beta$ and the strain hardening rate describe the speed or rate at which the microstructure of the material changes, whereas the current value of the strength corresponds to the current state of the microstructure. Therefore, it is intuitive that the strain hardening rate and the $\beta$ change similarly with plastic strain.

\section{Summary and Conclusions}

An equiatomic $\mathrm{CoCrFeMnNi}$ high-entropy alloy was produced by drop casting in argon atmosphere, homogenized, hot rolled, and characterized in compression at quasi-static and dynamic strain rates. The temperature increase of the samples during testing was measured with a high-performance IR camera. By combining the applied load and thermal data, the Taylor-Quinney coefficient was calculated and associated with the observed mechanical behavior. The main conclusions of this study can be summarized as the following:

(i) An increase in the mechanical strength was observed with increasing strain rate. The samples deformed at $1 \mathrm{~s}^{-1}$ had lower strength than those deformed at $10^{-2} \mathrm{~s}^{-1}$ at plastic strain higher than 0.4 .

(ii) Both the adiabatic heating and the $\beta$ are influenced by strain rate. The adiabatic heating at low strain rates is very small, but quickly increases when strain rate is increase. However, temperature rise and $\beta$ were noticeably similar among the samples deformed at 1,750 and $2800 \mathrm{~s}^{-1}$. 
(iii) The micro texture analysis due to compression shows that most of the grains are oriented towards $\{101\}$ planes that are parallel to compression direction, and the intensity of fiber texture $\{101\}$ is strain rate dependent, i.e. intensity increased with increase in strain rate.

Open Access This article is distributed under the terms of the Creative Commons Attribution 4.0 International License (http://creativeco mmons.org/licenses/by/4.0/), which permits unrestricted use, distribution, and reproduction in any medium, provided you give appropriate credit to the original author(s) and the source, provide a link to the Creative Commons license, and indicate if changes were made.

\section{References}

1. Cantor B, Chang ITH, Knight P, Vincent AJB (2004) Microstructural development in equiatomic multicomponent alloys. Mater Sci Eng A 375-377:213-218

2. Otto F, Dlouhý A, Somsen C, Bei H, Eggeler G, George EP (2013) The influences of temperature and microstructure on the tensile properties of a $\mathrm{CoCrFeMnNi}$ high-entropy alloy. Acta Mater 61:5743-5755

3. Thurston KVS, Gludovatz B, Hohenwarter A, Laplanche G, George EP, Ritchie RO (2017) Effect of temperature on the fatigue-crack growth behavior of the high-entropy alloy CrMnFeCoNi. Intermetallics 88:65-72

4. Li Z, Zhao S, Diao H, Liaw PK, Meyers MA (2017) High-velocity deformation of $\mathrm{Al}_{0.3} \mathrm{CoCrFeNi}$ high-entropy alloy: remarkable resistance to shear failure. Sci Rep 7:1-8

5. Eleti RR, Bhattacharjee T, Zhao L, Bhattacharjee PP, Tsuji N (2018) Hot deformation behavior of $\mathrm{CoCrFeMnNi}$ FCC high entropy alloy. Mater Chem Phys 210:176-186

6. Park JM, Moon J, Bae JW, Jang MJ, Park J, Lee S, Kim HS (2018) Strain rate effects of dynamic compressive deformation on mechanical properties and microstructure of $\mathrm{CoCrFeMnNi}$ high-entropy alloy. Mater Sci Eng A 719:155-163

7. Li Z, Zhao S, Alotaibi SM, Liu Y, Wang B, Meyers MA (2018) Adiabatic shear localization in the $\mathrm{CrMnFeCoNi}$ high-entropy alloy. Acta Mater 151:424-431

8. Kumar N, Ying Q, Nie X, Mishra RS, Tang Z, Liaw PK, Brennan RE, Doherty KJ, Cho KC (2015) High strain-rate compressive deformation behavior of the $\mathrm{Al}_{0.1} \mathrm{CrFeCoNi}$ high entropy alloy. Mater Des 86:598-602

9. Moon J, Hong SI, Bae JW, Jang MJ, Yim D, Kim HS (2017) On the strain rate-dependent deformation mechanism of CoCrFeMnNi high-entropy alloy at liquid nitrogen temperature. Mater Res Lett 5:472-477

10. Hong SI, Moon J, Hong SK, Kim HS (2017) Thermally activated deformation and the rate controlling mechanism in CoCrFeMnNi high entropy alloy. Mater Sci Eng A 682:569-576

11. Rittel D (1999) On the conversion of plastic work to heat during high strain rate deformation of glassy polymers. Mech Mater $31: 131-139$
12. Rittel D, Zhang LH, Osovski S (2017) The dependence of the Taylor-Quinney coefficient on the dynamic loading mode. J Mech Phys Solids 107:96-114

13. Farren WS, Taylor GI (1925) The heat developed during plastic extension of metals. Proc R Soc A Math Phys Eng Sci 107:422-451

14. Taylor GI, Quinney H (1934) The latent energy remaining in a metal after cold working. Proc R Soc A Math Phys Eng Sci 143:307-326

15. Prakash PR, Srivastava G (2019) Distributed plasticity model for analysis of steel structures subjected to fire using the direct stiffness method. Fire Saf J 105:169-187

16. Asad M, Ijaz H, Saleem W, Mahfouz A, Ahmad Z, Mabrouki T (2019) Finite element analysis and statistical optimization of endburr in turning AA2024. Metals (Basel) 9:276

17. Winter S, Pfeiffer S, Bergelt T, Wagner MFX (2019) Finite element simulations on the relation of microstructural characteristics and the formation of different types of adiabatic shear bands in a $\beta$-titanium alloy. IOP Conf Ser Mater Sci Eng 480:012022

18. Huang X, Ling Z, Dai LH (2019) Influence of surface energy and thermal effects on cavitation instabilities in metallic glasses. Mech Mater 131:113-120

19. Wang B, Fu A, Huang X, Liu B, Liu Y, Li Z, Zan X (2016) Mechanical properties and microstructure of the $\mathrm{CoCrFeMnNi}$ high entropy alloy under high strain rate compression. J Mater Eng Perform 25:2985-2992

20. Zaera R, Rodríguez-Martínez JA, Rittel D (2013) On the TaylorQuinney coefficient in dynamically phase transforming materials Application to 304 stainless steel. Int J Plast 40:185-201

21. Smith JL, Seidt JD, Gilat A (2019) Full-field determination of the Taylor-Quinney coefficient in tension tests of Ti-6Al-4V at strain rates up to 7000-1, pp 133-139.

22. Ma SG, Jiao ZM, Qiao JW, Yang HJ, Zhang Y, Wang ZH (2016) Strain rate effects on the dynamic mechanical properties of the $\mathrm{AlCrCuFeNi}_{2}$ high-entropy alloy. Mater Sci Eng A 649:35-38

23. Gorham DA, Wu XJ (2007) An empirical method of dispersion correction in the compressive Hopkinson bar test. Le J Phys IV 7:223-228

24. Meyers MA (1994) Dynamic behavior of materials. Wiley, Hoboken

25. Wei D, Li X, Jiang J, Heng W, Koizumi Y, Choi W-M, Lee B-J, Kim H-S, Kato H, Chiba A (2019) Novel Co-rich high performance twinning-induced plasticity (TWIP) and transformation-induced plasticity (TRIP) high-entropy alloys. Scr Mater 165:39-43

26. Yeh J-W (2016) Physical metallurgy. In: Gao MC, Yeh J-W, Liaw PK, Zhang Y (eds) High-entropy alloys: fundamentals and applications. Springer, New York, pp 51-113.

27. Varvenne C, Luque A, Curtin WA (2016) Theory of strengthening in FCC high entropy alloys. Acta Mater 118:164-176

28. He Q, Yang Y (2018) On lattice distortion in high entropy alloys. Front Mater 5:023404

Publisher's Note Springer Nature remains neutral with regard to jurisdictional claims in published maps and institutional affiliations. 